\title{
P75 neurotrophin receptor is sequestered in the Golgi apparatus of the U-87 MG human glioblastoma cell line
}

\author{
STÉPHANIE GIRAUD*, ELODIE LOUM*, BARBARA BESSETTE, \\ MURIEL MATHONNET and FABRICE LALLOUÉ
}

EA 3842, Homéostasie cellulaire et pathologies, Faculté de Médecine, 87025 Limoges, France

Received July 21, 2010; Accepted September 17, 2010

DOI: $10.3892 /$ ijo.2010.862

\begin{abstract}
The P75 neurotrophin receptor $\left(\mathrm{p} 75^{\mathrm{NTR}}\right)$ is a cell surface receptor that can induce apoptosis in many cell types. This receptor plays a major role in the development of the central nervous system and is expressed in some adult brain cells. Its implication in cell apoptosis or survival is probably of major importance in cellular homeostasis and thus p $75^{\mathrm{NTR}}$ could be implicated in tumor resistance to death. In this study, we investigated the intracellular expression of $\mathrm{p} 75^{\mathrm{NTR}}$ in a human glioblastoma cell line. Detection of $\mathrm{p} 75^{\mathrm{NTR}}$ receptor in Golgi apparatus by immunofluorescence microscopy, or after Golgi apparatus extraction, could be correlated with a decrease of cell apoptosis leading cells to become tumorous. This hypothesis is supported by a loss of ligand-induced apoptosis in this cell line. Our observations show that $\mathrm{p} 75^{\mathrm{NTR}}$ can be sequestered in the Golgi complex and could then be, in part, responsible for the cell resistance to apoptosis and for brain tumor formation.
\end{abstract}

\section{Introduction}

The neurotrophins (NT) such as nerve growth factor (NGF), brain-derived neurotrophic factor (BDNF), NT-3 and -4, use a two receptor system to promote cell differentiation, survival or cell death by apoptosis. These receptors are the low affinity neurotrophin receptor p75 (p75 $\left.{ }^{\mathrm{NTR}}\right)$ and the tyrosine kinase receptor (Trk) family. Each NT is specific for a Trk

Correspondence to: Dr B. Bessette, EA 3842, Homéostasie cellulaire et pathologies, Faculty of Medecine, 87025 Limoges, France E-mail: barbara.bessette@unilim.fr

${ }^{*}$ Contributed equally

Abbreviations: BDNF, brain-derived neurotrophic factor; BFA, Brefeldin-A; MFI, mean fluorescence intensity; NDGA, nordihydroguaiaretic acid; NGF, nerve growth factor; NT, neurotrophine; p75 ${ }^{\mathrm{NTR}}, \mathrm{p} 75$ neurotrophin receptor; TNFR/NGFR, tumor necrosis factor receptor/nerve growth factor receptor; Trk, tyrosine kinase receptor

Key words: $\mathrm{P} 75^{\mathrm{NTR}}$ receptor, Golgi apparatus, glioblastoma, glycosylation receptor, but all bind the $\mathrm{p} 75^{\mathrm{NTR}}$ with comparable affinities (1). P75 ${ }^{\mathrm{NTR}}$ is a glycoprotein that belongs to the tumor necrosis factor/nerve growth factor receptor family (TNFR/NGFR). This receptor is a type I transmembrane protein that contains an extracellular and an intracellular domain. The extracellular domain contains 4 repetitions of a 40-amino acid cysteine rich sequence, that can bind all of the four NTs, and a serinethreonine rich domain. The intracellular portion includes a death domain (2) and potential adaptator molecule-associated domains (3). NT interaction with cystein-rich domain of p $75^{\text {NTR }}$ induces different transduction pathways such as c-Jun N-terminal kinase (JNK) activation (4-6), sphingomyelin hydrolysis (7), nuclear transcription factor NF- $\mathrm{B}$ activation (8), caspase pathway activation $(9,10)$, activation of cell cycle regulatory molecules $(11,12)$ and p53 activation (13), leading to apoptosis, survival, differentiation or cell cycle regulation.

P75 ${ }^{\text {NTR }}$ is a glycoprotein of $75 \mathrm{kDa}$ when all post-transductional modifications are added. Phosphorylation occurs on serine and threonine residues and may regulate receptor multimerization $(14,15)$ and palmitoylation happens on cysteine 279 (16). Glycosylation of the receptor consists in a single asparagine-linked carbohydrate at position 33 located in the first cysteine repeat and several O-linked carbohydrates in the juxtamembrane stalk domain $(17,18)$. These posttraductional modifications take place in endoplasmic reticulum and Golgi apparatus.

The Golgi apparatus is a series of flattened, cisternal membrane structures forming the heart of the secretory pathway. The Golgi stack is a polarized structure with a cis-face, the cis-Golgi network (CGN), exchanging proteins and lipids with the endoplasmic reticulum (ER), and a transface, the trans-Golgi network (TGN), communicating with the plasma membrane and compartments of the endocytic pathway. As secretory materials pass through the Golgi in a cis to trans fashion, it becomes post-translationally modified in a sequential order before being sorted at the TGN for delivery to its final destination within the cell (19).

$\mathrm{P} 75^{\mathrm{NTR}}$ isoforms have been detected. They are produced both by alternative splicing and proteolysis. One splice variant of $\mathrm{p} 75^{\mathrm{NTR}}$ consisted in only lost of the first cystein-rich repeat in its extracellular domain (20). The splicing of the third exon of the $\mathrm{p} 75^{\mathrm{NTR}}$ transcript generated a variant that did not bind any of the NT because of the lack of cystein-rich domains 2, 3 and 4 but that could interfere with signaling transduction pathways. Full-length $\mathrm{p} 75^{\mathrm{NTR}}$ can also be cleaved 
by a constitutively active metalloproteinase to generate a soluble extracellular domain that is capable of binding neurotrophins and a receptor fragment containing the transmembrane and intracellular domains (21-23).

$\mathrm{P} 75^{\mathrm{NTR}}$ is a protein that is traditionally detected at the cell surface. Recently, involvement of p $75^{\mathrm{NTR}}$ in lipid rafts was shown and its contribution in signaling transduction confirmed (24). Lipid rafts concentrate lipids and proteins that function in transmembrane signaling events, allowing them to interact with each other and preventing them for interacting with molecules excluded from rafts. We studied the expression of $\mathrm{p} 75^{\mathrm{NTR}}$ protein in the Golgi apparatus of U-87-MG cells and the effects of neurotrophin treatments on this localization. We also studied the consequence of this sequestration on the apoptosis induced by a specific p $75^{\mathrm{NTR}}$ ligand.

\section{Materials and methods}

Cell line culture. Human glioblastoma cells U-87 MG (ATCC, Manassas, VA) were cultured in MEM with Earl' salts (Gibco BRL, Cergy Pontoise, France) supplemented with $10 \%$ decomplemented fetal calf serum (FCS), $1.5 \mathrm{~g} / 1$ sodium bicarbonate, $1 \%$ non-essential amino acids, sodium pyruvate (2 $\mathrm{mM})$, penicillin $(50 \mathrm{U} / \mathrm{ml})$, streptomycin $(50 \mathrm{U} / \mathrm{ml}), \mathrm{L}-$ glutamine $(2 \mathrm{mM})$ and fungizone $(0.1 \%)$ (Gibco BRL).

Cells were grown in a $25 \mathrm{~cm}^{2}$ flask (Sarstedt, Orsay, France) at $37^{\circ} \mathrm{C}$ in a humidified $5 \% \mathrm{CO}_{2}-95 \%$ air incubator. At sub-confluence, cells were recovered with versene (Gibco BRL) and cultured in Lab-Tek chamber slides at $10^{4}$ cells per well for immunocytochemistry or in 96-well plates at $10^{4}$ cells per well for apoptosis detection assays (Nunc, VWR, Strasbourg, France).

After 3 days in culture, different molecules were added prior to immunocytochemistry or functional assays: a human recombinant $\beta \mathrm{NGF}$ (50 $\mu \mathrm{M}$, ICN Biomedical, Irvine, CA), a human recombinant BDNF $(50 \mu \mathrm{M}$, Promega, Charbonnières, France), a mouse anti-p75 ${ }^{\mathrm{NTR}}$ monoclonal antibody (anti-p75 $\mathrm{mAb})$ without sodium azide $(50 \mu \mathrm{M}$, clone NGFR5, NeoMarkers, Fremont, CA, USA) for 48 h, Brefeldin-A (BFA, $10 \mu \mathrm{g} / \mathrm{ml}$, Sigma-Aldrich, Saint-Quentin Fallavier, France) for $2 \mathrm{~h}$, or nordihydroguaiaretic acid (NDGA, $10 \mu \mathrm{M}$, Sigma-Aldrich) for $24 \mathrm{~h}$. BFA is a fungal derived-substance known to cause apoptosis in different cell lines (25) by promoting retrogradous protein transport from the Golgi apparatus to the endoplasmic reticulum and that leads different components of Golgi complex to redistribute in a characteristic manner in all the cells (26-28). NDGA, known as a dual inhibitor for lipooxygenases and cyclooxygenases, inhibits the transport assay but also causes disassembly of the Golgi apparatus (29).

Immunofluorescence assays. In order to analyse receptors and ligands localisation, cell cultures were labeled at basal state or after exposure to BFA, NDGA, NGF or BDNF. Cells were fixed in $4 \%$ paraformaldehyde (Sigma-Aldrich) in PBS for $30 \mathrm{~min}$ at room temperature (RT) and permeabilized using alcool/acetone (v/v) for $5 \mathrm{~min}$ on ice. After a $90-\mathrm{min}$ saturation at RT with $10 \%$ goat serum (Sigma-Aldrich) in PBS, cells were incubated for $90 \mathrm{~min}$ at RT with primary antibodies diluted in saturating solution: anti-p75 ${ }^{\mathrm{NTR}}$ monoclonal antibody,
1/100 (clone NGFR5) and anti-p75 ${ }^{\text {NTR }}$ rabbit polyclonal antibody, 1/50 (anti-p75 ntAb, H-137, Santa Cruz Biotechnology, CA, USA) that both recognize the extracellular domain, anti-p $75^{\mathrm{NTR}}$ rabbit polyclonal antibody, 1/50 (anti-p $75^{\mathrm{NTR}}$ ctAb, H-92, Santa Cruz Biotechnology) that binds the intracellular domain, anti-mannosidase II rabbit antiserum, 1/200 [mannosidase II was shown to be a protein exclusively expressed in Golgi (30), Chemicon International, CA, USA], anti-golgin-97 mouse monoclonal antibody, 1/250 (clone CDF4, Molecular Probes, Leiden, The Netherlands), anti-TrkA mouse monoclonal antibody, 1/50 (clone 165131, R\&D Systems, Minneapolis, MN, USA), anti-TrkB mouse monoclonal antibody, 1/50 (clone 72509, R\&D Systems), anti-BDNF rabbit polyclonal antibody, 1/100 (Santa Cruz Biotechnology), anti-NGF rabbit polyclonal antibody, 1/100 (Santa Cruz Biotechnology). They were then revealed by a 30-min incubation with Alexa Fluor 488-conjugated goat anti-rabbit immunoglobulin (Ig) antibody (1/6000, Molecular Probes) and Alexa Fluor 594-conjugated goat anti-mouse Ig antibody (1/6000, Molecular Probes). Lipid rafts were detected with a cholera toxin B subunit FITCconjugated (Sigma-Aldrich), incubated during $20 \mathrm{~min}$ at $4^{\circ} \mathrm{C}$, at $1 / 200$ in PBS. Cells were fixed with glycerol gelatin (Sigma-Aldrich) and examined by confocal microscopy (Carl Zeiss S.A.S, LSM 510, Jena, Germany). Isotypic controls were realised using mouse IgG (Diaclone, Besançon, France) or rabbit Ig fraction (Dako Cytomation, Trappes, France).

Subcellular fractionation. Cells were washed twice in PBS and once in homogenization medium. After being resuspended in homogenization medium, cells were disrupted by 15 strokes in a Dounce homogenizer. Nuclei and unbroken cells were pelleted by centrifugation at $2000 \mathrm{~g}$ for $10 \mathrm{~min}$. Discontinuous Iodixanol gradients were made according to Graham et al (31) with some modifications. Iodixanol was diluted to a final concentration of 50\% Iodixanol, $0.25 \mathrm{M}$ sucrose, $1 \mathrm{mM}$ EDTA, and $10 \mathrm{mM}$ HEPES, pH 7.4, as the gradient stock solution. Different densities of Iodixanol were established by diluting this stock with $0.25 \mathrm{M}$ sucrose homogenization buffer. Gradients were then set up in $13 \mathrm{ml}$ Beckman SW41 centrifuge tubes by underlayering with a syringe and metal needle as follows: $2.5 \%$ Iodixanol, $1 \mathrm{ml} ; 5 \%, 2 \mathrm{ml} ; 7.5 \%, 2 \mathrm{ml} ; 10 \%$, $2 \mathrm{ml} ; 12.5 \%, 0.5 \mathrm{ml} ; 15 \%, 2 \mathrm{ml} ; 17.5 \%, 0.5 \mathrm{ml} ; 20 \%, 0.5 \mathrm{ml}$; and $30 \%, 0.3 \mathrm{ml}$. The vesicle fractions were loaded on top of the gradients and centrifuged in a SW41 rotor at 40,000 rpm for $2.5 \mathrm{~h}\left(4^{\circ} \mathrm{C}\right)$. The resulting gradient was collected in $500 \mu \mathrm{l}$ fractions. Iodixanol gradient material (OptiPrep, 60\% w/v) was purchased from Sigma-Aldrich.

Fractions rich in Mannosidase II activity (32) (not shown), an enzyme selectively localized into Golgi vesicles, were centrifuged at $20,000 \mathrm{~g}$ for $30 \mathrm{~min}$. The pellet obtained was resuspended in PBS with $0.25 \%$ Triton X-100.

Endoglycosidase digestion. Cells were washed once with PBS and lysed in appropriate buffer [PBS, $0.25 \%$ Triton X-100, $1 \mathrm{mM}$ phenylmethylsulfoxyfluoride, $1 \mu \mathrm{g} / \mathrm{ml}$ aprotinin, $1 \mu \mathrm{g} / \mathrm{ml}$ pepstatin A, $1 \mu \mathrm{g} / \mathrm{ml}$ leupeptin, $1 \mathrm{mM} \mathrm{NaF}$ and $1 \mathrm{mM} \mathrm{NaV}_{3} \mathrm{O}_{4}$ (Protease inhibitor cocktail set III, Calbiochem)]. After centrifugation at $14,000 \mathrm{~g}$ for $15 \mathrm{~min}$ at $4^{\circ} \mathrm{C}$, supernatants were collected. Protein concentrations were determined by the Bradford method (33) (Bio-Rad, Hercules, CA). 

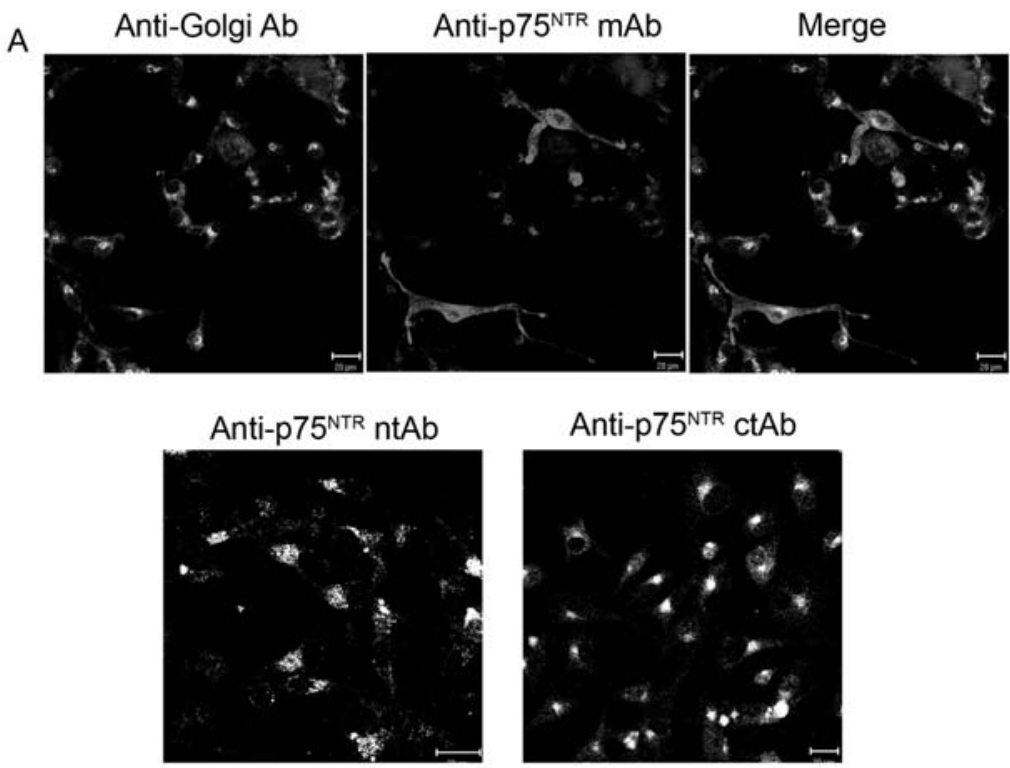

B

Anti-p $75^{\mathrm{NTR}} \mathrm{mAb}$

Permeabilized cells

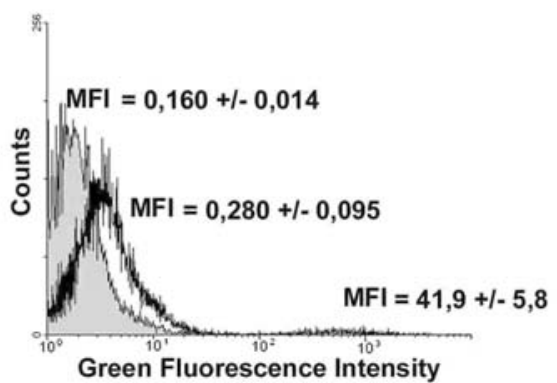

Unpermeabilized cells

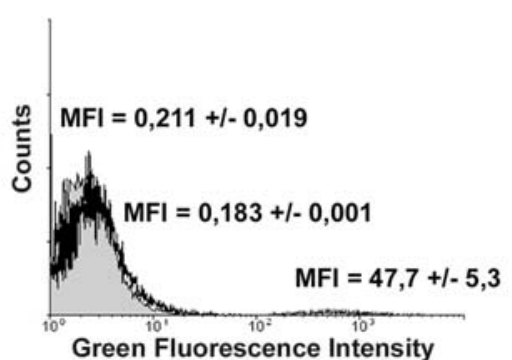

Figure 1. P75 ${ }^{\mathrm{NTR}}$ receptor was detected in Golgi apparatus by confocal microscopy. (A) Double-staining was performed with a mouse anti-p75 ${ }^{\mathrm{NTR}}$ monoclonal antibody (anti-p75 ${ }^{\mathrm{NTR}} \mathrm{mAb}$ ) and a rabbit anti-mannosidase II antibody (anti-Golgi Ab) on U-87 MG cell line (left panel). P75

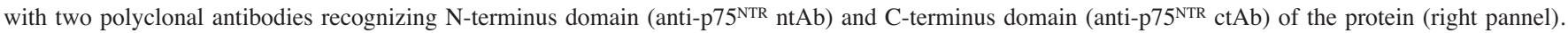
Primary antibodies were revealed by a goat anti-mouse Alexa Fluor 594-conjugated and a goat anti-rabbit Alexa Fluor 594 or 488-conjugated antibody. (B) U-87 MG cells were permeabilized or not, and stained with an anti-p75 ${ }^{\mathrm{NTR}} \mathrm{mAb}$ and goat anti-mouse Ig FITC-conjugated antibody and analyzed by flow cytometry. Mean fluorescence intensity (MFI), representative of 3 experiments, is indicated for each labelling and isotypic control was superimposed (in grey).

After denaturation, deglycosylation of $100 \mu \mathrm{g}$ of proteins was achieved by addition of $5 \mathrm{U}$ of peptide- $N$-glycosidase $\mathrm{F}$ (EC 3.5.1.52, Sigma-Aldrich) or $0.04 \mathrm{U}$ of $O$-glycosidase (EC 3.2.1.97, Sigma-Aldrich) and $1 \mathrm{U}$ of neuraminidase (EC 3.2.1.18, Sigma-Aldrich), with adequate buffers, according to the manufacturer. Digests were incubated at $37^{\circ} \mathrm{C}$ overnight.

Western blot analysis. Proteins (20 $\mu \mathrm{g})$ were boiled for $5 \mathrm{~min}$ in Laemmli buffer, separated by electrophoresis on NuPAGE 4-12\% Bis-Tris Gel (Invitrogen, Carlsbad, CA, USA) and transferred to nitrocellulose sheets (HAHY $0.45 \mu \mathrm{M}$, Millipore, St Quentin-Yvelines, France). After saturation with $5 \%$ non-fat dried milk in PBS, the sheets were incubated overnight at $4^{\circ} \mathrm{C}$ with anti-p75 mAb (1/200, NGFR5) diluted in $1.5 \%$ bovine serum albumin (Jacques Boy Institute S.A., Reims, France) in PBS and with mouse IgG1 (Diaclone) as isotypic control. After three washes in PBS and a 1-h incubation with an anti-mouse Ig peroxidase-labelled goat antiserum (1/1 000, Dako Cytomation), the sheets were revealed by the Covalight enhanced chemiluminescence procedure (AbCys, Paris, France).
Flow cytometry analysis. Cells were released from the flask with versene, permeabilized or not with Triton X-100 for 5 min at $4^{\circ} \mathrm{C}$ and resuspended in $10 \%$ FCS in versene with mouse anti-p75 ${ }^{\text {NTR }}$ monoclonal antibody (NGFR5) diluted at $1 / 40$ or mouse IgG1 Ig (Diaclone) as isotypic control. After a 30min incubation on ice, antibodies were detected with a goat anti-mouse Ig FITC-conjugated antibody (Dako Cytomation) diluted at $1 / 100$ in $10 \%$ FCS in versene during $30 \mathrm{~min}$, on ice. Finally, cells were resuspended and fixed in $10 \% \mathrm{FCS} / 1 \%$ paraformaldehyde in versene.

Each analysis was performed on at least 20,000 cells and repeated thrice. Relative fluorescence intensity was measured by fluorescence-activated cell sorter analysis (Epics XLMCL Coulter, Hialeah, FL, USA). Mean fluorescence intensity (MFI) was the mean of the three independent experiments.

Apoptosis detection by cell death detection ELISA plus. Cell apoptosis was evaluated using cell death detection ELISA plus (Roche Diagnostic, Meylan, France). Cells were seeded in wells of 96-multiwell plates $\left(10^{4}\right.$ cells/well) and maintained in culture 3 days. After a 48-h stimulation with an 

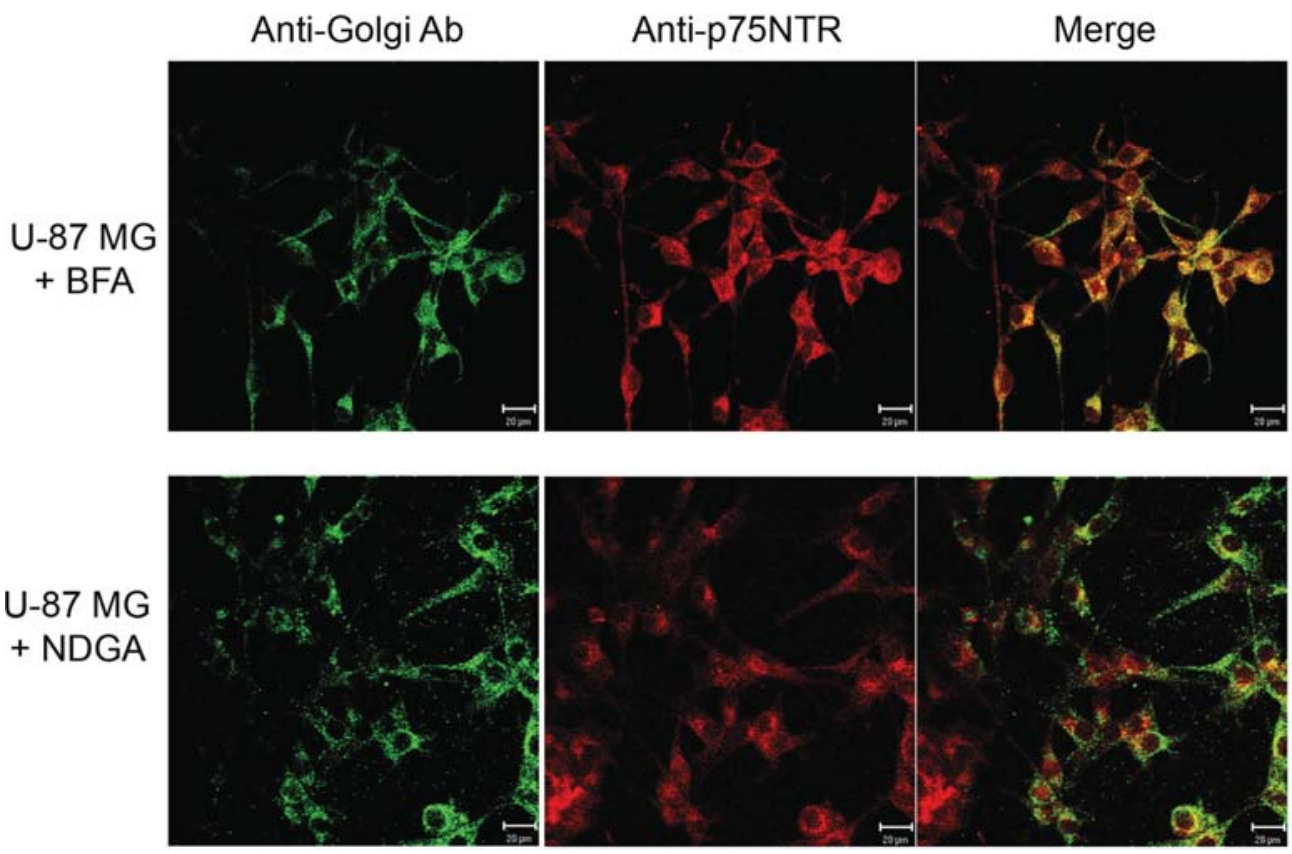

Figure 2. P75 ${ }^{\text {NTR }}$ immunolabelling is homogeneous in the cytoplasm of BFA and NDGA-treated cells. Double-staining was realized with a mouse anti-p75 ${ }^{\text {NTR }}$ monoclonal antibody (anti-p75 ${ }^{\mathrm{NTR}} \mathrm{mAb}$ ) and a rabbit anti-mannosidase II antibody (anti-Golgi Ab) on U-87 MG cell line, after treatments with BFA and NDGA, molecules that disrupt Golgi apparatus. A goat anti-mouse Alexa Fluor 594-conjugated and a goat anti-rabbit Alexa Fluor 488-conjugated antibody revealed the primary antibodies.

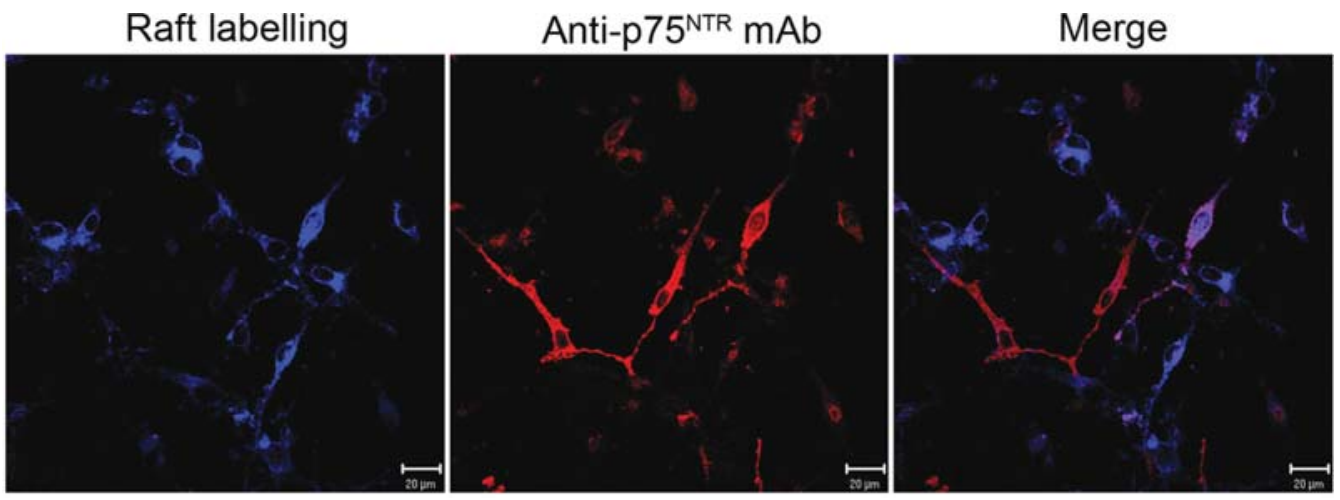

Figure 3. P75 ${ }^{\mathrm{NTR}}$ is not present in lipid rafts of U87-MG cells. P75 ${ }^{\mathrm{NTR}}$ labeling with a mouse anti-p75 ${ }^{\mathrm{NTR}}$ monoclonal antibody (anti-p75 $5^{\mathrm{NTR}}$ mAb) was observed on U-87 MG cells associated with raft labelling by cholera toxin B subunit FITC-conjugated. A goat anti-mouse Alexa Fluor 594-conjugated antibody revealed the primary antibody.

anti-p $75^{\mathrm{NTR}} \mathrm{mAb}$, rate of apoptosis was measured using cell death detection ELISA plus according to the manufacturer's instructions. This method differentiates the late apoptotic and necrotic cells. This ELISA simultaneously uses two monoclonal antibodies against DNA and histones to allow the specific detection of mono- and oligo-nucleosomes in the cytoplasmic fraction, characteristic for apoptosis. Absorbance values were measured at $405 \mathrm{~nm}$ with ELISA reader (Packard Instruments, Meriden, USA). Results were from three independent experiments.

Terminal transferase (TdT)-mediated dUTP nick-end labeling (TUNEL) assays. After a 48-h stimulation, cultured cells were fixed with $4 \%$ paraformaldehyde diluted in PBS for 30 min at room temperature, permeabilized with $0.1 \%$ Triton $\mathrm{X}-100$ during $5 \mathrm{~min}$ at $4^{\circ} \mathrm{C}$ and stained by the TUNEL method with
FITC labelling as described by the manufacturer (Promega) for $1 \mathrm{~h}$ at $37^{\circ} \mathrm{C}$. Reaction was stopped by a 10 -min wash in salt sodium citrate $2 \mathrm{X}$ and cells were counterstained with Evans' blue (Sigma-Aldrich). Cells were counted by fluorescence microscopy (Carl Zeiss S.A.S) with a magnification x200 (a minimum of 600 cells from 3 fields were counted for each conditions). Each assay was repeated thrice. Statistical analysis was performed using the t-test. A p $<0.05$ was considered as statistically significant.

\section{Results}

P75 ${ }^{\text {NTR }}$ protein is detected in Golgi apparatus. Immunocytochemical studies were performed with anti-p75 $5^{\mathrm{NTR}}$ antibodies on U-87 MG cells (Fig. 1A). The p75 ${ }^{\mathrm{NTR}}$ receptor was detected in the Golgi apparatus as confirmed by double-staining with 
A

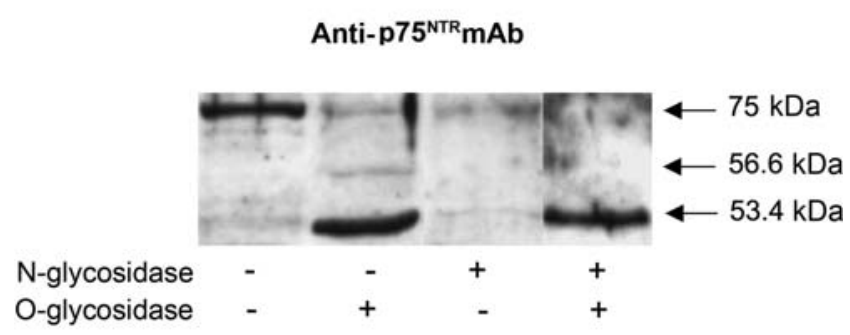

B

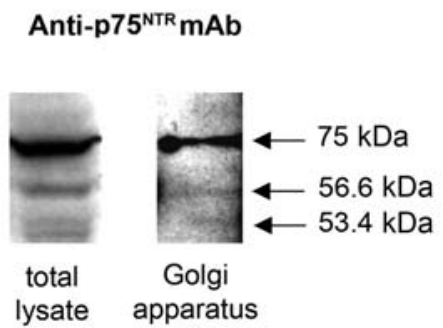

Figure 4. The $75 \mathrm{kDa}$ mature form of $\mathrm{p} 75^{\mathrm{NTR}}$ protein is present in Golgi apparatus. (A) U-87 MG cells were lysed, proteins were digested by $\mathrm{N}$ - and O-glycosidases, then separated on NuPAGE 4-12\% Bis-Tris Gel, transferred onto nitrocellulose sheets and detected using a mouse anti-p $75^{\mathrm{NTR}}$ monoclonal antibody (anti-p75 ${ }^{\mathrm{NTR}} \mathrm{mAb}$ ) or with mouse IgG1 Ig as isotypic controls (not shown). (B) After subcellular fractionation on discontinuous Iodixanol gradients, proteins of Golgi apparatus containing fractions were separated on NuPAGE 4-12\% Bis-Tris Gel, transferred onto nitrocellulose sheets and detected using a mouse anti-p75 ${ }^{\mathrm{NTR}}$ monoclonal antibody (anti-p $75^{\mathrm{NTR}} \mathrm{mAb}$ ) or with mouse IgG1 Ig as isotypic controls (not shown).

anti-p $75^{\mathrm{NTR}} \mathrm{mAb}$ and anti-mannosidase II antibodies (antiGolgi $\mathrm{Ab}$ ). The $\mathrm{p} 75^{\mathrm{NTR}}$ protein, near the nucleus, was detected with both anti-p75 ${ }^{\mathrm{NTR}}$ polyclonal antibodies, recognizing the $\mathrm{N}$-terminsal part of the protein (anti-p75 $\left.{ }^{\mathrm{NTR}} \mathrm{ntAb}\right)$ and the C-terminus part (anti-p75 ${ }^{\mathrm{NTR}} \mathrm{ctAb}$ ).

A p $75^{\text {NTR }}$ cell surface labelling was also detected by immunocytochemistry (Fig. 1A) and confirmed by flow cytometry (Fig. 1B), with the anti-p75 ${ }^{\mathrm{NTR}} \mathrm{mAb}$ (clone NGFR5) on U-87 MG cells. While p75 ${ }^{\mathrm{NTR}}$ receptor was generally detected into the cells (MFI $=0.280 \pm 0.095$, not detected when cells were not permeabilized), only $3 \%$ of U-87 MG cells expressed the $\mathrm{p} 75^{\mathrm{NTR}}$ receptor at cell surface $(\mathrm{MFI}=41.9 \pm 5.8$, Fig. 1B). Isotypic control (in grey) was realised and superimposed with immunolabelling.

BFA and NDGA disrupt Golgi apparatus and $775^{\text {NTR }}$ labelling. Both molecules, BFA and NDGA, that degrade the Golgi apparatus disrupted Golgi and p75 ${ }^{\mathrm{NTR}}$ labelling in U-87 MG cell lines (Fig. 2), confirming that the protein detected by the anti-p75 ${ }^{\mathrm{NTR}}$ antibodies was truly expressed in Golgi apparatus.

$P 75^{\text {NTR }}$ protein is not located in lipid rafts. Anti-p75 $5^{\mathrm{NTR}} \mathrm{mAb}$ and Raft double-stainings were performed on U-87 MG cell line, but no correlation could be observed, as no superimposable staining patterns were detected in cells expressing p75 ${ }^{\text {NTR }}$ at cell surface (Fig. 3).

The 75-kDa mature form of $p 75^{\text {NTR }}$ protein is present in Golgi apparatus. Molecular weights of proteins recognized by
A
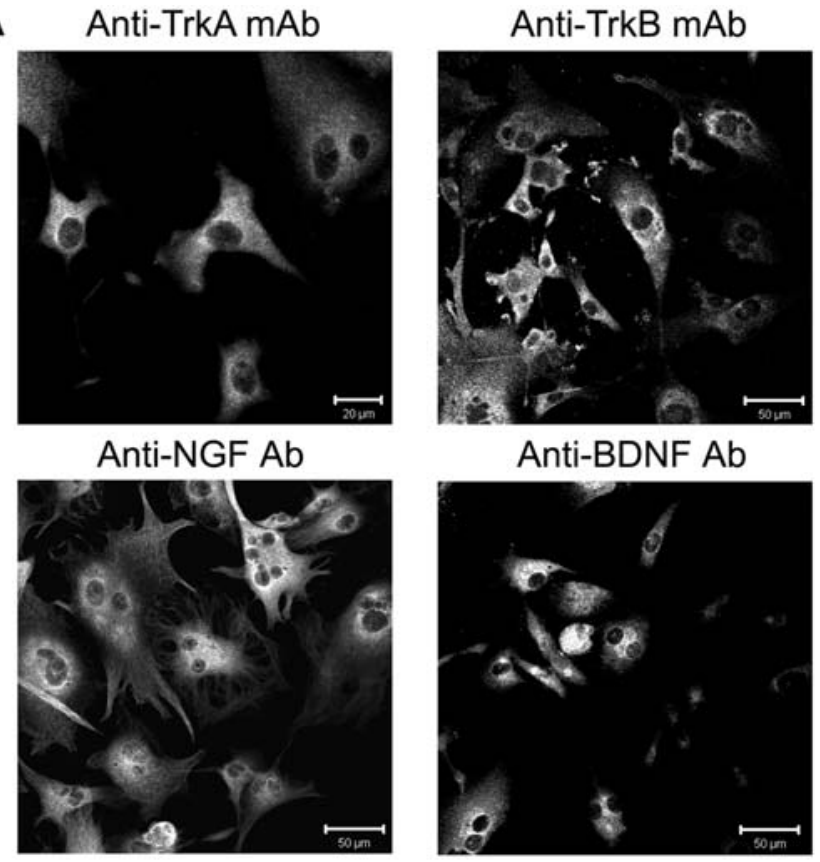

B
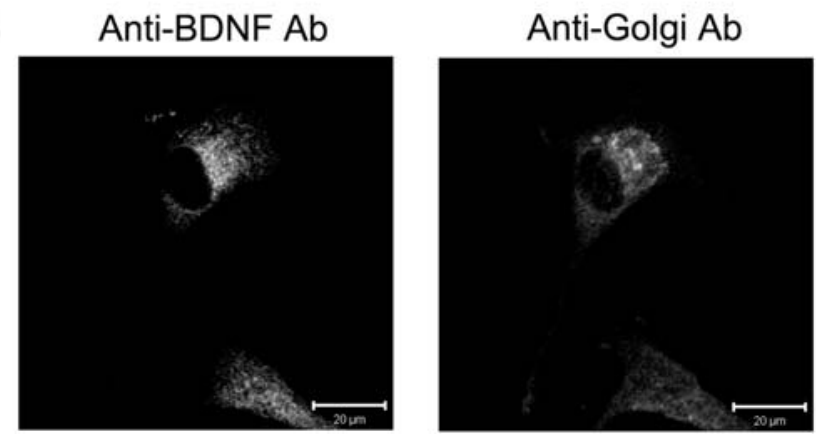

Figure 5. Presence of TrkA, TrkB, NGF and BDNF in U-87 MG cells. (A) Immunocytochemicals studies were performed with mouse anti-TrkA and -TrkB monoclonal antibodies, rabbit anti-NGF and -BDNF polyclonal antibodies on U-87 MG cells in basal condition. (B) Double-stainings were realized with a rabbit anti-BDNF polyclonal antibody and a mouse anti-Golgi antibody (anti-Golgi $\mathrm{Ab}$ ) on U-87 MG cells in basal condition. In (A) and (B), a goat anti-mouse Alexa Fluor 594-conjugated and a goat anti-rabbit Alexa Fluor 488-conjugated antibody revealed the primary antibodies.

anti-p75 $5^{\mathrm{NTR}}$ antibody were analyzed by Western blotting on U-87 MG cell line (Fig. 4). Different proteins were detected. Without enzymatic digestion (Fig. 4), 75 and $53.4 \mathrm{kDa}$ proteins were detected. A 56.6- kDa protein was occasionally detected (Fig. 4B). Endoglycosidase digestions of the total cell lysate showed that the $75 \mathrm{kDa}$ form of the protein is $\mathrm{N}$ and $O$-glycosylated. The $56.6-\mathrm{kDa}$ form appeared to be only $N$-glycosylated, whereas the 53.4-kDa form seemed to be neither $O$ - nor $N$-glycosylated.

After Golgi apparatus extraction, Western blot analysis of proteins showed that the three forms of the $\mathrm{p} 75^{\mathrm{NTR}}$ protein were present in Golgi apparatus (Fig. 4B). Isotypic controls were realized in order to verify non-specific labelling and no staining was observed (not shown).

Detection of TrkA, TrkB, NGF and BDNF in U-87 MG cells. Immunocytochemical studies were performed with anti-TrkA, -TrkB, -NGF and -BDNF antibodies on U-87 MG cells (Fig. 5A). TrkA and NGF were detected in the cells, whereas 


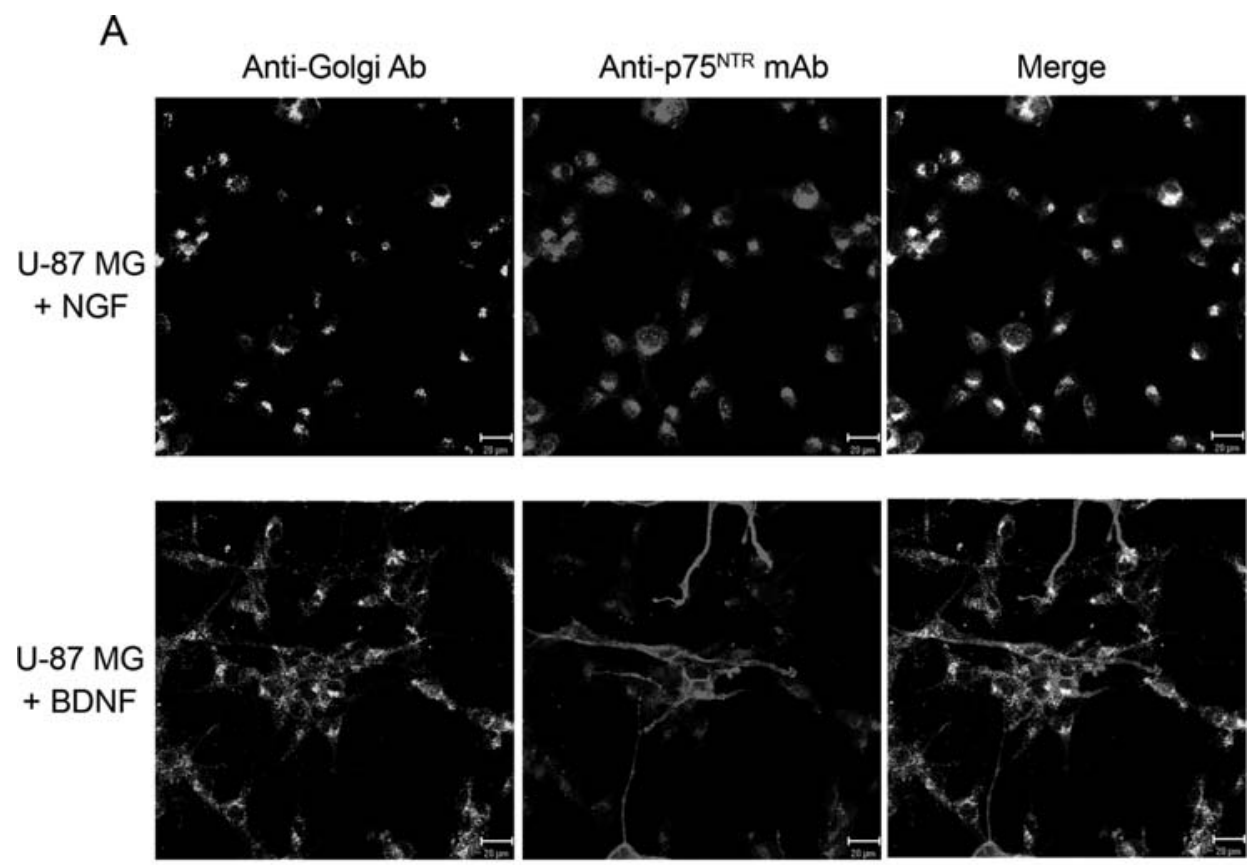

B

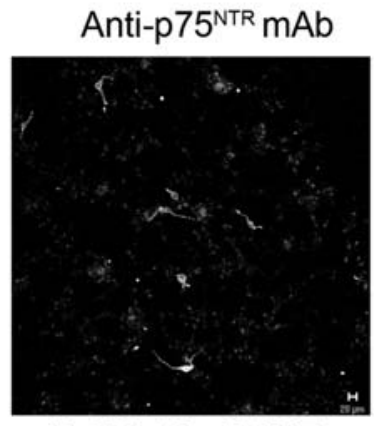

U-87 MG - BDNF

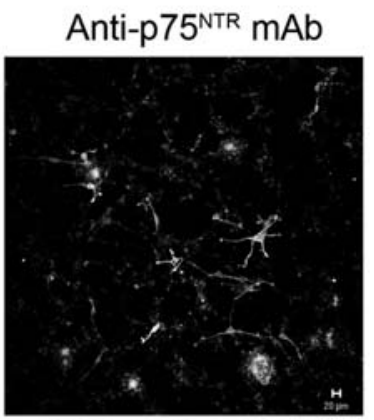

$\mathrm{U}-87 \mathrm{MG}+\mathrm{BDNF}$

Figure 6. Studies of p75 ${ }^{\mathrm{NTR}}$ cell surface expression after NGF and BDNF treatments. (A) Double-stainings were realized with a mouse anti-p75 ${ }^{\mathrm{NTR}}$ monoclonal antibody (anti-p75 ${ }^{\mathrm{NTR}} \mathrm{mAb}$ ) and a rabbit anti-mannosidase II antibody (anti-Golgi Ab) on U-87 MG cells after NGF or BDNF treatments. (B) P75 $5^{\mathrm{NTR}}$ labeling with a mouse anti-p $75^{\mathrm{NTR}}$ monoclonal antibody (anti-p $75^{\mathrm{NTR}} \mathrm{mAb}$ ) was observed on U-87 MG cells with or without BDNF and with a smaller magnification. A goat anti-mouse Alexa Fluor 594-conjugated and a goat anti-rabbit Alexa Fluor 488-conjugated antibody revealed the primary antibodies.

TrkB was also detected at cell membrane, and BDNF in Golgi apparatus (as confirmed by double-staining with antiBDNF and anti-Golgin antibodies, see Fig. 5B).

BDNF modifies the p $75^{N T R}$ receptor cell surface expression. The U-87 MG cell line was treated with NGF and BDNF for $48 \mathrm{~h}$. While NGF had no effect on $\mathrm{p} 75^{\mathrm{NTR}}$ protein localization in Golgi apparatus, BDNF changed its cell surface expression (Fig. 6A). Indeed, p75 ${ }^{\mathrm{NTR}}$ protein quantity in cell extensions seemed to be increased when cells were observed by immunofluorescence (Fig. 6B).

BDNF does not modify BDNF, TrkA and TrkB cell location. The U-87 MG cell line was treated with BDNF for $48 \mathrm{~h}$ and double-staining immunocytochemicals studies were performed with anti-BDNF and anti-p75 ${ }^{\mathrm{NTR}}$ antibodies, or with anti-TrkA and anti-p75 ${ }^{\mathrm{NTR}}$ antibodies, or with anti-TrkB and and anti-p75 ${ }^{\mathrm{NTR}}$ antibodies (Fig. 7). BDNF treatment had no effect on BDNF, TrkA and TrkB location, compared to basal. BDNF effect on p75 ${ }^{\mathrm{NTR}}$ cell surface expression decribed above was confirmed.

After BDNF treatment, $p 75^{N T R}$ protein is not co-localised with TrkB. After BDNF treatment, no correlation could be observed between $\mathrm{p} 75^{\mathrm{NTR}}$ and TrkB cell surface expression (Fig. 7C).

Apoptosis detection of cell lines submitted to p $75^{\text {NTR }} \mathrm{mAb}$ treatments. The anti-p75 mAb (clone NGFR5) effect on the U-87 MG cell line was analysed by both TUNEL and cell death detection ELISA plus methods (Fig. 8). Thus, whatever the method, no apoptosis variation was detected ( $p>0.3$ for all comparisons).

\section{Discussion}

P75 ${ }^{\mathrm{NTR}}$ protein was usually detected at cell surface. In this report, this receptor has been localized in the Golgi apparatus 
A

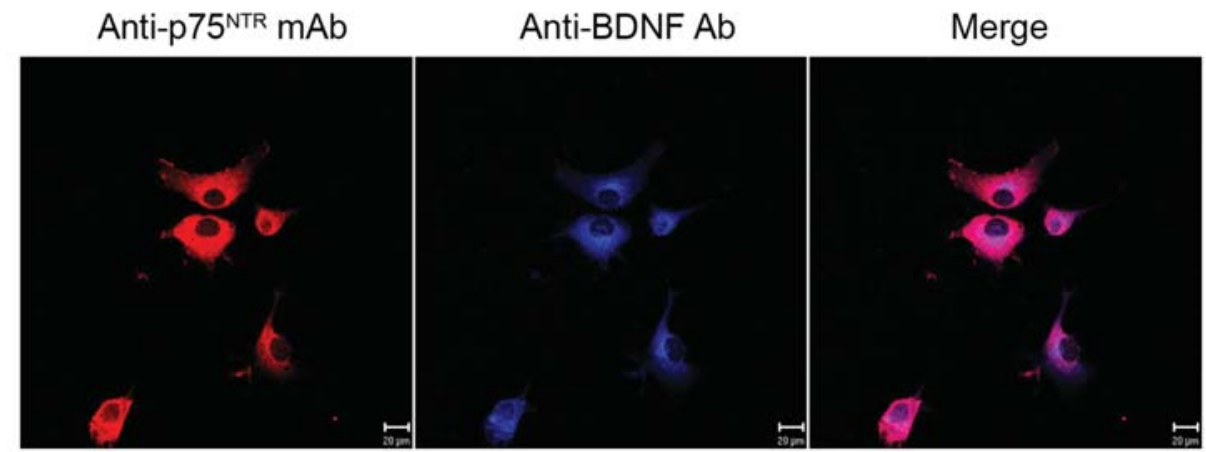

B

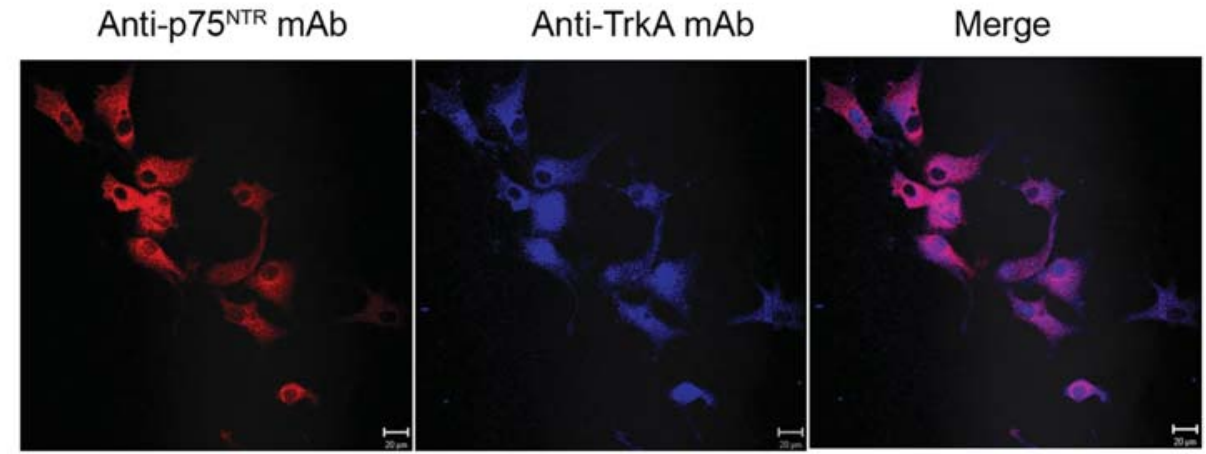

C

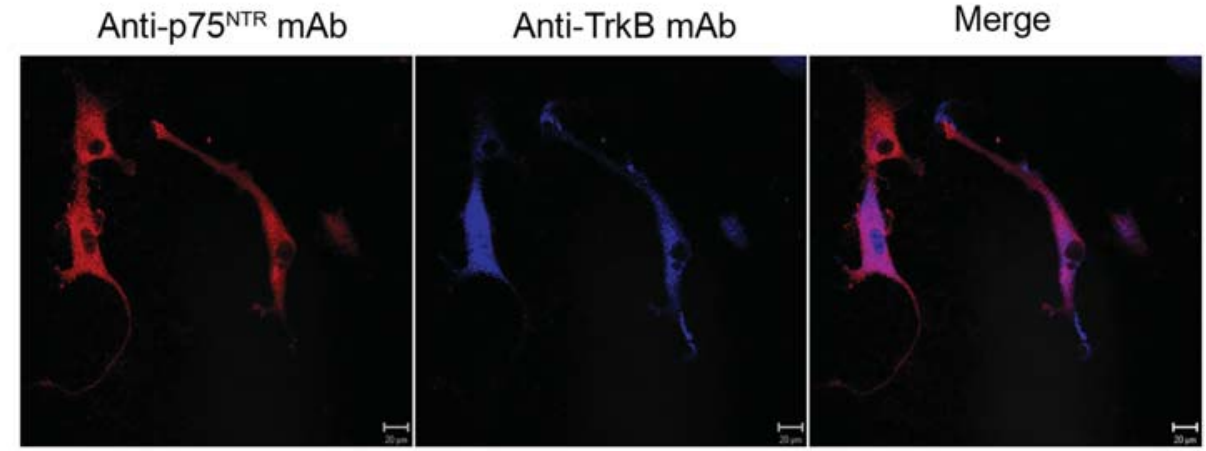

$U-87 M G+B D N F$

Figure 7. BDNF effects on BDNF, TrkA and TrkB cell location is compared with p75 ${ }^{\mathrm{NTR}}$ cell surface expression. After BDNF cell line treatment (48 h), double-staining immunocytochemicals studies were performed with a rabbit anti-BDNF polyclonal and a mouse anti-p75 ${ }^{\mathrm{NTR}}$ monoclonal antibodies (A), with a mouse anti-TrkA monoclonal and a rabbit anti-p $75^{\mathrm{NTR}}$ polyclonal antibodies (B), and with a mouse anti-TrkB monoclonal and a rabbit anti-p75 ${ }^{\mathrm{NTR}}$ polyclonal antibodies (C). A goat anti-mouse Alexa Fluor 594-conjugated and a goat anti-rabbit Alexa Fluor 488-conjugated antibody revealed the primary antibodies.

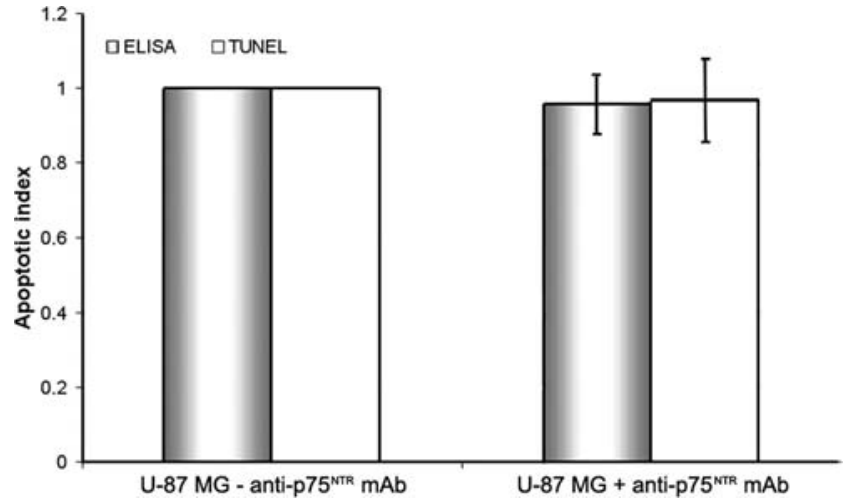

Figure 8. P75 ${ }^{\text {NTR }}$ activation did not change the apoptotic level of U87-MG cells. Apoptotic level of U87-MG cells after anti-p75 ${ }^{\mathrm{NTR}}$ monoclonal antibody exposure for $48 \mathrm{~h}$ were determined by cell death detection ELISA plus and TUNEL methods. of U-87 MG cells. Indeed, p75 $5^{\mathrm{NTR}}$ immunolabelling showed strong staining near the nucleus, suggesting that $\mathrm{p} 75^{\mathrm{NTR}}$ protein was localized in the Golgi apparatus. This hypothesis was confirmed by double-staining with both anti-p $75^{\mathrm{NTR}}$ and anti-Golgi antibody, as they stained the same area of cells. Furthermore, $\mathrm{p} 75^{\mathrm{NTR}}$ labelling was modified when cells were submitted to molecules that degrade Golgi apparatus, confirming that $\mathrm{p} 75^{\mathrm{NTR}}$ protein was truly localized in the Golgi apparatus. The use of polyclonal antibodies that recognized respectively $\mathrm{p} 75^{\mathrm{NTR}} \mathrm{N}$ - and $\mathrm{C}$-terminus domains, confirmed these results and suggested that $\mathrm{p} 75^{\mathrm{NTR}}$ is present in Golgi apparatus in it full length form. Nevertheless, some U-87 MG cells expressed $\mathrm{p} 75^{\mathrm{NTR}}$ at the cell surface, but at low rate.

The analysis of p75 ${ }^{\mathrm{NTR}}$ molecular weight by Western blotting showed three main bands. Deglycosylation analysis demonstrates that the 53.4-kDa protein corresponded to p $75^{\mathrm{NTR}}$ receptor without $N$ - and $O$-glycosylation, the $56.6 \mathrm{kDa}$ 
to the $N$-glycosylated form and the $75 \mathrm{kDa}$ to the mature receptor. Yeaman et al (34) showed that N-glycans are not necessary for sorting of p75 ${ }^{\mathrm{NTR}}$ at MDCK cell membrane, and that structural information for apical sorting of the receptor at membrane is localized to a juxtamembrane region of the extracellular domain that is rich in $O$-glycosylated serine/threonine residues. However, in our study, the mature $O$-glycosylated form of $7^{\text {NTR }}$ protein is localized in Golgi apparatus. Moreover, $O$-glycosylation was shown to be crucial for protein cell surface expression and may regulate association with rafts (35). In contrast with this result, no clear relation between $\mathrm{p} 75^{\mathrm{NTR}}$ cell surface receptors and raft localization could be pointed out in U87-MG cells. As p75 phosphorylation was described to be implicated in $\mathrm{p} 75^{\mathrm{NTR}}$ lipid raft localization (36), it would be interesting to study p75 ${ }^{\mathrm{NTR}}$ phosphorylation in U87-MG cell line. Otherwise, the presence of $O$-glycosylations is a prerequisite for exit from the ER and protection from intracellular cleavage of $\mathrm{p} 75^{\mathrm{NTR}}$ (35). The data are in accordance with the presence of the full length and $O$-glycosylated form of p75 $5^{\text {NTR }}$ in Golgi complex of U87-MG cells, as demonstrated in our study.

The localization of the neurotrophins NGF and BDNF and their receptors, TrkA and TrkB, were studied in U-87 $\mathrm{MG}$ cells. Interestingly, as p75 ${ }^{\mathrm{NTR}}$ receptor, BDNF was detected in Golgi apparatus and could be the result of their internalization. Indeed, internalization of neurotrophins and their receptors are well documented. Kahle and Hertel (37) presented evidence that rat glial cells are able to sequester NGF from the cell surface to an intracellular compartment, and that $\mathrm{p} 75^{\mathrm{NTR}}$ may mediate this internalization. Moreover, Bronfman et al (38) showed a ligand-induced internalization of the p $75^{\mathrm{NTR}}$ receptor in PC12 cells. In their model, both internalized ligand and receptor were protected from proteolytic degradation and accumulated in vesicles that did not undergo acidification. Alderson et al (39) demonstrated that cultured hippocampal astrocytes and schwann cells specifically bind and internalize BDNF and NT-4/5. Moreover, they showed that a substantial portion of the endocytosed pool of neurotrophins is released back into the extracellular medium without obvious degradation. In retinal ganglion cells, NT-3, NGF and BDNF accumulate transiently in the Golgi system (40). The NT-3 lysosomal pathway and the anterograde transport from Golgi apparatus involve binding to the $\mathrm{p} 75^{\mathrm{NTR}}$ receptor. Taken together, these data are consistent with the presence of BDNF and p75 ${ }^{\mathrm{NTR}}$ in the Golgi apparatus of U-87 MG cells, as demonstrated in our study. Since TrkB was present at U-87 MG cell surface as well as in the cytosol, this receptor could be involved in BDNF internalization.

Thus, in U-87 MG cells, p75 ${ }^{\mathrm{NTR}}$ protein is sequestered in the Golgi complex and not fully expressed at the cell surface. Like this receptor, two proteins belonging to the TNF receptor superfamily were reported to be detected in the Golgi apparatus. CD95 (Fas) membrane expression was shown to be regulated by sequestration in the Golgi complex in B-cell lymphoma (41). Moreover, Bradley et al (42) showed that $55 \mathrm{kDa}$, but not $75 \mathrm{kDa}$, TNF receptors were predominantly localized in the Golgi apparatus of endothelial cells. As for Fas receptor, $\mathrm{p} 75^{\mathrm{NTR}}$ retention in the Golgi complex may therefore be an important mechanism for preventing $\mathrm{p} 75^{\mathrm{NTR}}$ cell surface expression in glial cells, which may be of direct relevance for brain tumor pathogenesis. This hypothesis seems to be confirmed by the fact that treatment with the anti-p75 ${ }^{\mathrm{NTR}} \mathrm{mAb}$ did not increase the cell apoptotic rate of $\mathrm{U}-87 \mathrm{MG}$ cells, while $\mathrm{p} 75^{\mathrm{NTR}}$ protein is reported to be a proapoptotic receptor in glioblastoma cell line $(43,44)$. This receptor sequestration may be a way for tumor cells to escape from apoptosis due to neurotrophin binding. Thus, induction of $\mathrm{p} 75^{\mathrm{NTR}}$ expression on cell surface might be an interesting way to improve tumor apoptosis.

In order to study the effects of $\mathrm{p} 75^{\mathrm{NTR}}$ classical ligands, NGF and BDNF, we first tested the presence at cell surface of the neurotrophin receptors TrkA and TrkB in U-87 MG cells. The fact that NGF treatment did not change the expression pattern of p $75^{\mathrm{NTR}}$ is in accordance with the absence of TrkA at U-87 MG cell surface. However, BDNF treatment seemed to increase the $\mathrm{p} 75^{\mathrm{NTR}}$ receptor cell surface expression, which might be promoted by the presence of TrkB at cell surface. Bennett et al (45) showed that Fas is sequestered in Golgi apparatus of human vascular smooth muscle cells. Interestingly, p53 activation transiently increases Fas surface expression by transport from the Golgi complex. Moreover, p53-induced apoptosis of these cells requires surface transport of the receptor. Contrary to Fas which targets the cell surface during pro-apoptotic treatment in this model, p75 ${ }^{\mathrm{NTR}}$ in U-87 MG cells studied seemed here to require differentiation and proliferation factor (as BDNF) for targeting the cell surface. Thus, it would be of interest to submit U-87 MG cells to Fas$\mathrm{L}$ treatment or other apoptosis inducing molecules, and to study eventual redistribution of $\mathrm{p} 75^{\mathrm{NTR}}$. Considering that the decision of cell survival or death depends on the presence or absence of Trk receptors coexpressed with $\mathrm{p} 75^{\mathrm{NTR}}$ at cell surface (46), we looked for their eventual colocation after BDNF treatment: no correlation could be established between $\mathrm{p} 75^{\mathrm{NTR}}$ and TrkB or TrkA cell surface locations. Thus, whether this redistribution of $\mathrm{p} 75^{\mathrm{NTR}}$ at cell surface represents a pathway for differentiation, proliferation or death of U-87 MG cells remains to be clarified.

Intracellular sequestration of death receptors, like p75 ${ }^{\mathrm{NTR}}$ in U87-MG cells, may cause resistance to apoptosis and insensitivity to chemotherapeutic agents for cancer. Conversely, a therapy based on cell surface redistribution of death receptors through endogenous ligands remains to be studied, but also requires the understanding of the consequent signaling pathways.

\section{Acknowledgements}

This work was supported by grants from Conseil Régional du Limousin and Ligue Nationale Contre le Cancer (comités de la Corrèze et Haute Vienne).

\section{References}

1. Bothwell M: Functional interactions of neurotrophins and neurotrophin receptors. Annu Rev Neurosci 18: 223-253, 1995.

2. Liepinsh E, Ilag LL, Otting G and Ibanez CF: NMR structure of the death domain of the p75 neurotrophin receptor. EMBO J 16: 4999-5005, 1997.

3. Roux PP and Barker PA: Neurotrophin signaling through the p75 neurotrophin receptor. Prog Neurobiol 67: 203-233, 2002. 
4. Casaccia-Bonnefil P, Carter BD, Dobrowsky RT and Chao MV: Death of oligodendrocytes mediated by the interaction of nerve growth factor with its receptor p75. Nature 383: 716-719, 1996.

5. Bamji SX, Majdan M, Pozniak CD, et al: The p75 neurotrophin receptor mediates neuronal apoptosis and is essential for naturally occurring sympathetic neuron death. J Cell Biol 140: 911-923, 1998.

6. Yoon SO, Casaccia-Bonnefil P, Carter B and Chao MV: Competitive signaling between TrkA and p75 nerve growth factor receptors determines cell survival. J Neurosci 18 : 3273-3281, 1998.

7. Dobrowsky RT, Jenkins GM and Hannun YA: Neurotrophins induce sphingomyelin hydrolysis. Modulation by co-expression of $\mathrm{p} 75^{\mathrm{NTR}}$ with Trk receptors. J Biol Chem 270: 22135-22142, 1995.

8. Carter BD, Kaltschmidt C, Kaltschmidt B, Offenhäuser N, Böhm-Matthaei R, Baeuerle PA and Barde YA: Selective activation of NF-kappa B by nerve growth factor through the neurotrophin receptor p75. Science 272: 542-545, 1996.

9. Gu C, Casaccia-Bonnefil P, Srinivasan A and Chao MV Oligodendrocyte apoptosis mediated by caspase activation. J Neurosci 19: 3043-3049, 1999.

10. Wang X, Bauer JH, Li Y, Shao Z, Zetoune FS, Cattaneo E and Vincenz C: Characterization of a p75(NTR) apoptotic signaling pathway using a novel cellular model. J Biol Chem 276: 33812-33820, 2001 .

11. Park DS, Levine B, Ferrari G and Greene LA: Cyclin dependent kinase inhibitors and dominant negative cyclin dependent kinase 4 and 6 promote survival of NGF-deprived sympathetic neurons. J Neurosci 17: 8975-8983, 1997.

12. Frade JM: Unscheduled re-entry into the cell cycle induced by NGF precedes cell death in nascent retinal neurones. J Cell Sci 113: 1139-1148, 2000

13. Aloyz RS, Bamji SX, Pozniak CD, Toma JG, Atwal J, Kaplan DR and Miller FD: p53 is essential for developmental neuron death as regulated by the TrkA and p75 neurotrophin receptors. J Cell Biol 143: 1691-1703, 1998.

14. Grob PM, Ross AH, Koprowski H and Bothwell M: Characterization of the human melanoma nerve growth factor receptor. J Biol Chem 260: 8044-8049, 1985.

15. Taniuchi M, Johnson EM Jr, Roach PJ and Lawrence JC Jr: Phosphorylation of nerve growth factor receptor proteins in sympathetic neurons and PC 12 cells. In vitro phosphorylation by the cAMP-independent protein kinase FA/GSK-3. J Biol Chem 261: 13342-13349, 1986

16. Barker PA, Barbee G, Misko TP and Shooter EM: The low affinity neurotrophin receptor, p75LNTR, is palmitoylated by thioester formation through cysteine 279. J Biol Chem 269: 30645-30650, 1994

17. Johnson D, Lanahan A, Buck CR, et al: Expression and structure of the human NGF receptor. Cell 47: 545-554, 1986.

18. Large TH, Weskamp G, Helder JC, Radeke MJ, Misko TP, Shooter EM and Reichardt LF: Structure and developmental expression of the nerve growth factor receptor in the chicken central nervous system. Neuron 2: 1123-1134, 1989.

19. Short B, Haas A and Barr FA: Golgins and GTPases, giving identity and structure to the Golgi apparatus. Biochim Biophys Acta 1744: 383-395, 2005.

20. Dechant $G$ and Barde YA: Signalling through the neurotrophin receptor p75 ${ }^{\mathrm{NTR}}$. Curr Opin Neurobiol 7: 413-418, 1997.

21. Zupan AA, Osborne PA, Smith CE, Siegel NR, Leimgruber RM and Johnson EM Jr: Identification, purification, and characterization of truncated forms of the human nerve growth factor receptor. J Biol Chem 264: 11714-11720, 1989.

22. Barker PA, Miller FD, Large TH and Murphy RA: Generation of the truncated form of the nerve growth factor receptor by rat Schwann cells. Evidence for post-translational processing. J Biol Chem 266: 19113-19119, 1991.

23. Di Stefano PS, Clagett-Dame M, Chelsea DM and Loy R: Developmental regulation of human truncated nerve growth factor receptor. Ann Neurol 29: 13-20, 1991.

24. Paratcha $G$ and Ibanez $C F$ : Lipid rafts and the control of neurotrophic factor signaling in the nervous system: variations on a theme. Curr Opin Neurobiol 12: 542-549, 2002.
25. Salles FT, Hespanhol AM, Jaeger RG and Marques MM: Brefeldin-A induces apoptosis in human adenoid cystic carcinoma cultured cells. Oral Oncol 40: 585-590, 2004.

26. Lippincott-Schwartz J, Yuan LC, Bonifacino JS and Klausner RD Rapid redistribution of Golgi proteins into the ER in cells treated with brefeldin A: evidence for membrane cycling from Golgi to ER. Cell 56: 801-813, 1989.

27. Reaves B and Banting G: Perturbation of the morphology of the trans-Golgi network following Brefeldin A treatment: redistribution of a TGN-specific integral membrane protein, TGN38. J Cell Biol 116: 85-94, 1992.

28. Alvarez C and Sztul ES: Brefeldin A (BFA) disrupts the organization of the microtubule and the actin cytoskeletons. Eur J Cell Biol 78: 1-14, 1999.

29. Yamaguchi T, Yamamoto A, Furuno A, Hatsuzawa K, Tani K, Himeno $\mathrm{M}$ and Tagaya $\mathrm{M}$ : Possible involvement of heterotrimeric $\mathrm{G}$ proteins in the organization of the Golgi apparatus. J Biol Chem 272: 25260-25266, 1997.

30. Moremen KW and Touster O: Biosynthesis and modification of Golgi mannosidase II in HeLa and 3T3 cells. J Biol Chem 260: 6654-6662, 1985.

31. Graham J, Ford T and Rickwood D: The preparation of subcellular organelles from mouse liver in self-generated gradients of iodixanol. Anal Biochem 220: 367-373, 1994.

32. Storrie B and Madden EA: Isolation of subcellular organelles. Methods Enzymol 182: 203-225, 1990.

33. Bradford M A: Rapid and sensitive method for the quantitation of microgram quantities of protein utilizing the principle of protein-dye binding. Anal Biochem 72: 248-254, 1976.

34. Yeaman C, Le Gall AH, Baldwin AN, Monlauzeur L, Le Bivic A and Rodriguez-Boulan E: The O-glycosylated stalk domain is required for apical sorting of neurotrophin receptors in polarized MDCK cells. J Cell Biol 139: 929-940, 1997.

35. Breuza L, Garcia M, Delgrossi MH and Le Bivic A: Role of the membrane-proximal O-glycosylation site in sorting of the human receptor for neurotrophins to the apical membrane of MDCK cells. Exp Cell Res 273: 178-186, 2002.

36. Higuchi H, Yamashita T, Yoshikawa H and Tohyama M: PKA phosphorylates the $\mathrm{p} 75$ receptor and regulates its localization to lipid rafts. EMBO J 22: 1790-1800, 2003.

37. Kahle $P$ and Hertel $C$ : Nerve growth factor (NGF) receptor on rat glial cell lines. Evidence for NGF internalization via p75NGFR. Biol Chem 267: 13917-13923, 1992.

38. Bronfman FC, Tcherpakov M, Jovin TM and Fainzilber M: Ligand-induced internalization of the p75 neurotrophin receptor: a slow route to the signaling endosome. J Neurosci 23: 3209-3220, 2003.

39. Alderson RF, Curtis R, Alterman AL, Lindsay RM and Di Stefano PS: Truncated TrkB mediates the endocytosis and release of BDNF and neurotrophin-4/5 by rat astrocytes and Schwann cells in vitro. Brain Res 871: 210-222, 2000.

40. Butowt R and von Bartheld CS: Sorting of internalized neurotrophins into an endocytic transcytosis pathway via the Golgi system: ultrastructural analysis in retinal ganglion cells. J Neurosci 21: 8915-8930, 2001

41. Haynes AP, Daniels I, Abhulayha AM, Carter GI, Metheringham R, Gregory CD and Thomson BJ: CD95 (Fas) expression is regulated by sequestration in the Golgi complex in B-cell lymphoma. Br J Haematol 118: 488-494, 2002.

42. Bradley JR, Thiru S and Pober JS: Disparate localization of $55-\mathrm{kDa}$ and $75-\mathrm{kDa}$ tumor necrosis factor receptors in human endothelial cells. Am J Pathol 146: 27-32, 1995.

43. Bhakar AL, Howell JL, Paul CE, et al: Apoptosis induced by p $75^{\text {NTR }}$ overexpression requires Jun kinase-dependent phosphorylation of Bad. J Neurosci 23: 11373-11381, 2003.

44. Yamaguchi $\mathrm{H}$, Ukita $\mathrm{H}$, Murakami $\mathrm{H}$, et al: Induction of apoptosis through $\mathrm{NGF} / \mathrm{p} 75^{\mathrm{NTR}}$ in human glioma cells treated with propentofylline. No To Shinkei 50: 407-414, 1998.

45. Bennett M, Macdonald K, Chan SW, Luzio JP, Simari R and Weissberg P: Cell surface trafficking of Fas: a rapid mechanism of p53-mediated apoptosis. Science 282: 290-293, 1998.

46. Chao MV and Hempstead BL: p75 and Trk: a two-receptor system. Trends Neurosci 18: 321-326, 1995. 